\title{
Analysis of Different Tendencies Towards Individualism and Collectivism From the Perspective of Genders
}

\author{
Juan Guo ${ }^{1, a}$, Hao Liu ${ }^{2, b^{*}}$ and Ming Zhou ${ }^{3}$ \\ 1,2,3 Nanjing University of Finance and Economics, Nanjing, Jiangsu, China \\ a juanitajuan@163.com, ${ }^{b}$ liuhaoleo@163.com \\ * The Corresponding Author
}

Keywords: Collectivism; Individualism; Gender

\begin{abstract}
With the pace of the globalization process, cross-cultural communication today is becoming more and more frequent, and the researches on cross-cultural communication have been increasing day by day. In 1980, Hofstede put forward the four dimensions on cultural differences, making a groundbreaking research result in the field of cross-cultural communication. In 1991, Triandis concluded that the two tendencies in the "collectivism/individualism" dimension (I-C dimension) not only exist between different cultures, but also in the same culture, the same society, the same group, or even the same person. In this paper, 50 subjects are surveyed under the collectivism/individualism dimension of Hofsted and Triandis, and the data are analyzed to check Hofstede's study on Chinese collectivism and to analyze the different tendencies of different sexes in the collectivism/individualism dimension.
\end{abstract}

\section{Introduction}

With the high speed of economic globalization and great advancement of civilization, "global village" advanced by Marshall Mcluhan in his book Understanding Media (1964) was once only a concept but nowadays has nearly become a reality. People from different cultures have more opportunities to communicate with each other. And more and more scholars turn to the research of inter-cultural communication. Intercultural communication study originated from America. As early as in 1959, Edward T. Hall published Silent Language, marking the beginning of intercultural study. In the 1980s, intercultural communication research comprehensively began in America and spread out all over the world.

In 1980, Hofstede originally identified four cultural dimensions: (1) power distance, (2) uncertainty avoidance, (3) individualism \& collectivism, (4) masculinity \& femininity. From then on, the individualism/collectivism dimension has been widely used to compare differences between cultures. Afterward, Hofstede conducted a further research on his four cultural value dimensions by investigating workers from 50 countries and 3 regions. According to his major findings at I-C dimension, China obtained higher numbers on collectivism, which meant China could be classified as collective.

In 1989, Triandis published his Cross-Cultural Studies of Individualism and Collectivism, in which he estimated that "about $70 \%$ of the population of the world lives in collective cultures." (Triandis, 1989:48) He also found that orientations toward individualism and collectivism not only existed between different cultures but also within one culture, even within each society and each individual.

The questions the present study mainly aims to answer are as follows: 1) Is the opinion by Hofstede that China largely belongs to collectivistic culture, still correct in China now? 2) Do different orientations toward I-C exist between males and females? And what is the tendency like? 


\section{Significance of the Study}

Firstly, the paper can change the westerners' stereotype toward Chinese people to some degree and help them have a better knowledge of Chinese cultural value to promote the mutual understanding of people from different cultures and guarantee successful intercultural communication.

Secondly, in the present study, the author tries to investigate from the perspective of genders, and enhance the mutual understanding between males and females in China to avoid misunderstanding which may be developed into quarrels and conflicts, and do harm to our feelings.

\section{Literature Review}

Relevant Studies at Home and Abroad. In the process of comparing cultural differences, many researchers focus on the study of cultural value. They want to find out from what dimension we can differentiate people's behavior efficiently and have a better perception of them.

Geert Hofstede is one of the earliest scholars who applied extensive statistical data to test cultural values. From 1967 to 1973, he analyzed data from more than 100,000 individuals in multinational institutions from forty countries, and then employed statistical methods to examine the responses to the surveys. After careful analysis, in 1980, he published a book entitled Cultural Consequences: International Differences in Work Related Values, where the individualism and collectivism dimension was firstly identified. Subsequently, he developed his earlier theory on cultural values into a theory of the four value dimensions. In order to examine them, Hofstede investigated thousands of workers in multinational organizations from 50 countries and three regions.

Triandis spent almost 30 years of research in cross-cultural field and put forward the individualism and collectivism theory (1995), which was from a quite different point of view. He further developed Hofstede's I-C theory to a large degree. He argues that individualism and collectivism are not two opposite poles or a single cultural dimension but two major factors and a comprehensive culture synthesis which are composed of four universal facets: 1) The self-definition is interdependent in collectivist culture and independent in individualist culture. 2) Personal and communal goals are closely aligned in collectivism and not at all aligned in individualism. 3) Cognitions which emphasize on norms, obligations, and duties direct much of social behavior in collectivistic society. 4) A stress on relationships, even when they are unfavorable, collectivistic society.

In 1998, Samovar L.A. published Communication between Culture, in which he used the cultural dimension of Hofstede's individualism/collectivism to explore cultural diversity and pointed out that individualism and collectivism are learned through the family which teaches children whom they must follow and in their lives who are the dominant figures.

In study of forced compliance, Hiniker (1999) in his research found that Chinese participants show much compliance but little change in attitude.

Up to the $21^{\text {st }}$ century, Chinese scholars began to lay more emphasis on the cultural difference in this field. Li Qiao (2005) did a comparative study on Sino-American cultural value. He mainly focused on exploring approaches to promote mutual understanding and suggested that we should develop the competence of foreign language as well as the acquisition of cultural background knowledge and overcome cultural stereotypes.

Based on Hofstede's value dimension theory, Fan Ying (2006) conducted a comparative study between American individualism and Chinese collectivism which was . In the thesis, she put forward a hypothesis that China is generally a collectivistic country and America an individualistic one with their respective features.

$\mathrm{Li} \mathrm{Yu} \mathrm{(2006)} \mathrm{pointed} \mathrm{out} \mathrm{though} \mathrm{some} \mathrm{individualistic} \mathrm{traits} \mathrm{have} \mathrm{come} \mathrm{up,} \mathrm{specially} \mathrm{among} \mathrm{the}$ younger generation, the collectivism, as the core cultural value, has not yet been completely altered. She also argues that under the new situation Hofstede's I-C binary dimension may no more be applicable to the changing society. They may have shared quite a few overlapping cultural traits in place of being at the opposite ends of I-C dimension. 
Ning Fang (2008) used the latest VSM08 instrument developed by Professor Hofstede to examine the effects of nationality, employment, age and gender in two phases. Compared with the previous findings, Chinese people are still more toward collectivism pole than the Americans, but the distance seems to be shortened between the two. In the second phase, results show that the effects of gender on value orientation are found out on the individualism index only, where the score of males are much higher than that of females.

Hou Caihong (2008) compared privacy in Sino-American cultures, based on Hofstede's I-C theory and Hall's proxemics theory and drew a conclusion: privacy in China is collectivism-featured whereas American privacy is individualism-featured.

Yang Xiaofeng (2009) introduced different manifestations of I-C from perspective of literature in Chinese. He pointed out the literature in the individualistic/collectivistic cultural background reflected the cultural values respectively.

Wang Huan (2010) aims at how the I-C influences people's behaviors and is manifested in discourse in communication. The thesis shows that in the way of expression and building up the identity of self, Americans are more individualistic while Chinese are relatively collectivistic in these aspects.

\section{Methodology}

Research Questions. The paper aims to answer the following questions: 1) Is the opinion by Hofstede that China largely belongs to collectivistic culture, still correct in China now? 2) Do different orientations toward I-C exist between males and females? And what is the tendency like?

Subjects. The 50 subjects (males: 25; females: 25 ) involved in the survey are mainly composed of college students and teachers from different majors. Totally, there are 45 shares (males: 21; females: 24) of valid questionnaire in the survey. We use mean scores in the process of data analysis, so that the numbers of males and females are not the same is okay. All these feedback will be analyzed on the general tendency toward I-C. Then they will be categorized according to genders, and have a detailed comparison of the specific orientations toward I-C dimension.

Instruments. For the collection of data, the present study adopts the questionnaire as the major instrument. In order to ensure its scientificity, interviews are conducted before the questionnaires are designed.

In order to reduce the subjectivity and improve the scientificity of the questionnaire, interviewing, as an efficient method, has been adopted for the information collection on the development of the statements in the questionnaire. The interviewees are 2 teachers and 2 students and the interviews are carried out in a very casual and pleasant atmosphere.

The questionnaire is made up of two parts: Part A is collectivism-oriented survey and part B is individualism-oriented one. In the experiment, the respondents are asked to tick out the most appropriate answer among the five provided answers which vary from strongly disagree to strongly agree according to what degree they agree on a 5-point scale for the purpose of facilitating the actualization of the investigation. All the 20 items in the questionnaire are scored on the 5-point scales (1-2-3-4-5).

It is known to all that the cultural value exists in the every aspect of life. Despite the same group of people, they may manifest different I-C tendencies in the different domains. Five domains are determined, which are country, workplace, family, friends and individual life. In the survey, the author is especially eager to find out what tendencies different groups of people at different layers present respectively. There are 4 items for each domain. A1.2 and B1.2 test the people's tendencies toward I-C at the country layer, A3.-4 and B3.4 at the work level, A5.6 and B5.6 at the family layer, A7.8 and B7.8 at the friend level and A9-10 and B9-10 at the individual life layer. 


\section{Results and Discussion}

A General Comparison between All the Subjects. This part tries to answer the first research question--whether Chinese people still have a general tendency toward collectivism in the new global cross-cultural communicative situation or not.

In order to test the validity of Hofstede's I-C theory about China that Chinese culture largely belongs to collectivistic culture, what we need to do is to test the mean scores in I-C respectively.

Table 1 Comparison within All Subjects

\begin{tabular}{|l|l|l|}
\hline Questionnaire Part & Number & Mean Score \\
\hline A & 45 & 41 \\
\hline B & 45 & 26 \\
\hline
\end{tabular}

It is shown that the mean scores of Part A and Part B of the 45 subjects are 41 and 26 respectively. The mean score of Part A toward collectivism is much higher than that of Part B toward individualism. So Chinese people in general display an obvious tendency toward collectivism, which proves Hofstede's I-C theory about China is true. Chinese people still have a strong inclination to collectivism because Confucianism, as a decisive factor in Chinese cultural tradition, which has been passed from one generation to another, has exerted a very deep influence even on average Chinese people.

According to the questionnaire, the mean score of each part is higher than the mid-point of the full score, which indicates that these participants present obvious tendencies toward either of the two types of orientations which are collectivism-oriented and individualism-oriented. Although Chinese has a general tendency toward collectivism, in I-C dimension, the individual differences are a real existence.

Table 2 Different Tendencies Within All Subjects

\begin{tabular}{|c|c|c|}
\hline Type & Number & Percentage \\
\hline $\mathrm{C}>\mathrm{I}$ & 41 & $91 \%$ \\
\hline $\mathrm{C}<\mathrm{I}$ & 3 & $7 \%$ \\
\hline $\mathrm{C}=\mathrm{I}$ & 1 & $2 \%$ \\
\hline Total & 45 & $100 \%$ \\
\hline
\end{tabular}

Notes: $\mathrm{C}>\mathrm{I} \rightarrow$ Collectivism score is higher than individualism score. $\mathrm{C}<\mathrm{I} \rightarrow$ Collectivism score is lower than individualism score. $\mathrm{C}=\mathrm{I} \rightarrow$ Collectivism score is equal to individualism score.

Seeing from the second row of table 2, we can find that there are 41 subjects whose collectivism scores are higher than individualism scores. The third row of the table shows us there are only 3 subjects whose collectivism scores are lower than individualism scores. Finally we can find from the fourth row of the table that there is only one subject who gets equal collectivism and individualism score. The finding obtained from table 2 indicates that: 1) there are 41 subjects, $91 \%$ of all the subjects display more obvious tendency to collectivism than to individualism. 2) Only 3 subjects, $7 \%$ of all the subjects, show a more significant tendency toward individualism than toward collectivism.

The result, from the other side, proves the previous conclusion drawn by Hofstede (1980) again that China largely belongs to the collective country and most Chinese have a strong tendency to be collectivists. It is also consistent with Triandis' I-C theory that tendencies to individualism and collectivism not only exist between cultures but also within one culture, even within a society or an individual for there are subjects who manifest as both collectivists and individualists, who manifest as either collectivists or individualists and who manifest as neither collectivists nor individualists. Obviously, it is very necessary to check the detailed differences in the different tendencies to I-C dimension in different specific domains.

\section{A Detailed Comparison between Genders}

In this part, the author aims to find out the different tendencies toward I-C from the perspective of genders. A general and specific comparison between males and females is included.

The General Different Orientations on I-C between Genders 
Table 3 General Difference between Genders

\begin{tabular}{|c|c|c|}
\hline Questionnaire Part & Gender & Mean score \\
\hline \multirow{2}{*}{ A } & Males & 42 \\
\cline { 2 - 3 } & Females & 41 \\
\hline \multirow{2}{*}{ B } & Males & 30 \\
\cline { 2 - 3 } & Females & 22 \\
\hline
\end{tabular}

It gives us an implication that there is no significant difference between males and females in part A (collectivism-oriented). That is to say, the two genders have the same significant tendency toward collectivism. However, in part B, there are significant differences between genders as the mean scores of males and females in part B are 30 and 22 respectively, which indicate that males have much stronger tendency toward individualism than women. That is to say, to some degree, males are more individualistic than females. What is more, the mean scores of males and females in part A are 42 and 41 respectively, which are much higher than those of the two genders in part B. In other words, both males and females in China show a significant tendency toward collectivism in general. The result proves the previous conclusion reached by Hofstede (1980) that most Chinese display collective tendency.

According to Hofstede(1980), China belongs to masculine society and most men in China own superior position and higher social status in the family and society due to their special social roles. They emphasize on self-concept and pay attention to their own emotions and feelings and they are free to express their opinions. As a result, males are more likely to manifest a stronger tendency toward individualism. Before the foundation of the PRC, China is an agricultural country with a long feudalistic history and traditional Confucian culture. In ancient China, that the men plough and the women weave are the vivid picture of people's life of that time. Even in the Chinese modern society, that the husband mainly ought to deal with the social affairs while the wife ought to do the domestic affairs is the true picture of a typical family life in China. Men are often regarded as the bread-earners of the whole family and they should be responsible for many social duties. They often need to take part in different social activities and they have more opportunities and accesses to the outside world and meet with new concept and ideas. Chinese women often play a supportive role in the family and are relatively conservative because of their social roles. Most Chinese women, especially in the rural area, are of the family type. They live a life of helping husband and teaching the children. Compared with men, they have less chance to go out for the social affairs and get in touch with the new things and ideas in the current society. The impact from the outside world has little influence on them. Therefore, most women in China keep the features of traditional Chinese culture. It is not strange to find that they show a stronger tendency toward the pole of collectivism than men.

The finding also echoes with the traditional gender norms in China. Men are often encouraged to behave like men, to be strong and manly, to be independent and autonomous, to be reliable and responsible, and not to cry before others or express feelings and emotions too easily since their early childhood. On the contrary, women ought to be tender, understanding, interdependent, and so on.

The Specific Different Orientations toward I-C at Different Layers between Genders

Table 4 Specific Difference at Different Layers between Genders

\begin{tabular}{|c|c|c|}
\hline Domains & Gender & Mean score \\
\hline \multirow{2}{*}{ Country } & Males & 15 \\
\cline { 2 - 3 } & Females & 16 \\
\hline \multirow{2}{*}{ Work } & Males & 16 \\
\cline { 2 - 3 } & Females & 16 \\
\hline \multirow{2}{*}{ Family } & Males & 15 \\
\cline { 2 - 3 } & Females & 19 \\
\hline \multirow{2}{*}{ Friend } & Males & 14 \\
\cline { 2 - 3 } & Females & 18 \\
\hline \multirow{2}{*}{ Individual Life } & Males & 11 \\
\cline { 2 - 3 } & Females & 10 \\
\hline
\end{tabular}


Column 1 of table 4 is about the five different domains. When we consider the mean scores of I-C in column 2, we find that at the country, workplace and individual life levels, males and females show no significant differences in I-C dimension. However, at the family and friend layers, the two genders have strong differences in the two domains. The higher mean scores mean the stronger tendency toward collectivism. According to column 2, we can find that both at the family and friend levels, females show much stronger tendency toward collectivism than males.

In the old times, women in China were regarded as the disadvantaged groups in the society just as Hofstede (1980) concluded that China belongs to a country of masculinity. Due to the different social division of labor from males, most women in China are of the family type and family-centered. They often play a supportive role in the family compared with men. They mainly take the responsibility for helping their husbands, looking after their children and doing housework. They have lower social status and are used to restraining their own emotions and needs and caring about others' feeling. They often pay more attention to trivial things of their family.

Nowadays, with the open-policy in China, women become more independent and have more rights than before. Most Chinese women, especially in the urban area, go out to work. But when their interests and their family interests conflict, they are even willing to sacrifice their own benefits and needs on behalf of other members of their in-group, especially their family members. Therefore, it is reasonable that women present a stronger tendency toward collectivism than men at the family layer. As mentioned above, women show a stronger tendency toward collectivism than men not only at the family level but also at the friend level. To some extent, their character has a great effect on the orientations in I-C dimension. Generally speaking, females are supposed to be tender, good-hearted, considerate (other-oriented), interdependent and gifted in communication. Women are talkative and crazy about chatting with their friends about anything in life. When they confront hardships or troubles in their real life, they are willing to come to their friends for discussions and suggestions. Meanwhile, they care about others and are ready to help friends when they are in difficulties. They want to share happiness and sorrows with their friends. As women are timid and interdependent, they like to be accompanied by friends. Therefore, in the daily life, it is quite a commonplace to see women hand in hand, crying and laughing together or going shopping with their friends. However, it is quite a strange phenomenon to see men whine to their friends as males often talk less but do more than females. It is natural to find women manifest a more significant tendency toward collectivism at both the family and friend levels than men.

\section{Conclusion}

Major Findings. The present thesis based on Triandis' I-C theory aims to make an exploratory study on the different tendencies of different genders toward individualism and collectivism in general and at the different layers. The data analysis has produced the following findings.

1) All the subjects show a stronger tendency toward collectivism than to individualism through comparing the mean scores of them.

2) Considering genders, males and females have no significant difference in part A and both of them show a strong tendency toward collectivism. But in part B they have significant differences and males tend to be more individualistic than females. In addition, at the family and the friend layers, females tend to be more collectivistic than males. In other words, males are more individualistic than females.

Limitations. Despite the findings and implications stated above, the current study still has some unavoidable limitations due to the limited time and condition. The limitations are mainly reflected in aspects of instruments and subjects.

1) The first limitation lies in the self-made questionnaire. Although the questions were designed on the basis of the related statement of Triandis and Hofstede at I-C dimension and the group interviews, the validity and reliability still need further testing and improving.

2) The second limitation is the subjects. The distribution of people is somehow uneven. This may more or less have some negative effect on the collected data analysis. Furthermore, all these 45 
subjects come from the same city due to the limited time and some actual difficulties, which may also affect the validity of the investigation.

In the future study, the attention should be paid to the variety of the subjects from different places. A wider range of subjects from different places with different social backgrounds will make the conclusions more convincing.

\section{Acknowledgements}

This paper is financially aided by the project "Research on Development Path of Jiangsu Language Service Industry under the Perspective of Cultural Industry" (Project No. L-HZW16001) funded by universities' philosophy and social science researches in Jiangsu Province.

\section{References}

[1] E. T. Hall, Beyond culture, Anchor, Essex, 1976.

[2] J. Hiniker, American Character and Culture in a Changing World, Greenwood Press, Westport, 1999.

[3] G. Hofstede, Culture's consequences: International differences in work-related values, Sage Publication, New York, 1980.

[4] M. Mcluhan, Understanding Media: The Extensions of Man, McGraw-Hill, New York, 1964.

[5] L.A. Samovar, Porter, R. E. and McDaniel, E. R. Communication between Cultures, Wadsworth, Toronto, 1998.

[6] H. C. Triandis: submitted to Nebraska Symposium on Motivation (1989).

[7] H. C. Triandis, Individualism and Collectivism (New Directions in Social Psychology), Westview Press, Boulder, 1995.

[8] H. C. Triandis, Theoretical Concepts That Applicable to the Analysis of Ethnocentrism, Sage Publications, New York, 1991.

[9] Y. Fan, A Contrast and Analyses between American Individualism and Chinese Collectivism, PLA Foreign Language University, 2006.

[10] C. H. Hou, Privacy and Intercultural Communication-A Contrastive Study of Privacy in Chinese and American Cultures, Shanghai Normal University, 2008.

[11] Q. Li, Sino-American Cultural Value-Differences and Mutual Understanding, Tianjin University of Technology, 2005.

[12] Y. Li, Reconsidering the Binary Individualism/Collectivism Dimension: Are Modern Chinese and American Cultures at Opposite Ends of Hofsteded's Line, Shanghai International Studies University, 2006.

[13] F. Ning, An Exploratory Study on the Cultural Values of China's Post-1980s Generation, Shanghai International Studies University, 2008.

[14] H. Wang, Individualism and Collectivism Manifested in Discourse-A Comparative Study of Sino-American Acceptance Speech, Shanghai Normal University, 2010.

[15] X. F. Yang: submitted to Henan Social Sciences (2009). 